\title{
Helping people to live well with chronic kidney disease
}

\author{
Authors: Simon Fraser $^{1}$ and Maarten Taal $^{2}$ \\ 1. School of Primary Care, Population Sciences and Medical Education, Faculty of Medicine \\ University of Southampton
}

2. Division of Medical Sciences and Graduate Entry Medicine, University of Nottingham

\section{Introduction}

In this paper we will be considering some of the implications of having chronic kidney disease (CKD), discussing what we know of the experience of the condition from the patient perspective, and, based on these issues, addressing how we as clinicians can best help people to 'live well' when they have the diagnosis.

In the last decade CKD has courted a degree of controversy. It has been included in debates on 'too much medicine' with concerns about over-labelling individuals with a 'disease' and the resulting burden and costs of clinical assessment, investigations, and 'unnecessary' treatment for both patients and health services (Moynihan et al. 2013). On the other hand, it is clearly a condition with a wide spectrum of severity, from a minor degree of reduced kidney function, often identified as an incidental finding, to life-changing end stage kidney disease (ESKD) requiring complex decisions about kidney replacement therapy (KRT, dialysis or transplantation) or conservative care. And it is not just ESKD that presents clinical challenges - there is now incontrovertible evidence that any degree of kidney dysfunction or damage is strongly associated with poor outcomes for patients. Large, international meta-analyses of both high risk and general population cohort studies have shown that any degree of low estimated glomerular filtration rate (eGFR) and albuminuria are both independent risk factors for poor outcomes including all-cause and cardiovascular mortality (CKD Prognosis Consortium 2010 and van der Velde et al. 2011), cardiovascular disease (Matsushita et al. 2015), progression of CKD, hospitalisation, and acute kidney injury (AKI) (Gansevoort et al. 2011; Astor et al. 2011; Grams et al. 2015).

This has understandably left some clinicians with uncertainty about how best to approach management, particularly in early or moderate CKD. Should the condition be played down as 'not that important' and possibly not even disclosed to patients as it may cause unnecessary distress? Or should its identification be prioritised with a view to early intervention to allow the best possible opportunity for the prevention of progression to end stage disease or other complications?

We hope that this paper will unpick some of these issues and provide some useful strategies with practical clinical application while keeping the person with CKD at the centre of the discussion.

\section{Classification and epidemiology of CKD}

The Kidney Disease Improving Global Outcomes (KDIGO) risk classification of CKD includes both reduced excretory function (by estimated glomerular filtration rate (eGFR)) and kidney damage (by presence of albuminuria) (KDIGO 2013). eGFR is categorised into six stages $-\mathrm{G} 1\left(\geq 90 \mathrm{ml} / \mathrm{min} / 1.73 \mathrm{~m}^{2}\right)$ to $\mathrm{G} 5$ (eGFR $<15 \mathrm{ml} / \mathrm{min} / 1.73 \mathrm{~m}^{2}$ ), and albuminuria into three groups (A1 reflecting urine albumin to creatinine ratio (uACR) $<3 \mathrm{mg} / \mathrm{mmol}$ to $A 3$ indicating $u A C R \geq 30 \mathrm{mg}$ per $\mathrm{mmol}$ ) (KDIGO 2013).

CKD is common; prevalence in England is estimated at between 12 and $13 \%$ of the population, based on the nationally-representative Health Survey for England (and including both eGFR and UACR), rising to over $30 \%$ among people over 75 years (Fraser et al. 2014). While it is important to note that this was based on a single eGFR measure, and studies basing their CKD definition on two values of eGFR at least 90 days apart, as per KDIGO guidelines, have found lower prevalence, prevalence of eGFR 
$<60 \mathrm{ml} / \mathrm{min} / 1.73 \mathrm{~m}^{2}$ was still $16 \%$ among people aged over 60 in the Oxford Renal Cohort Study (Hirst et al. 2018). Future incidence and prevalence is likely to reflect a balance between the growing, ageing population, and increasing prevalence of obesity and type two diabetes, against improving hypertension control and falling smoking prevalence (Hounkpatin et al. 2020). As these population demographics and risk factors change over time, it is also likely that patients who have CKD as one of their health problems are increasingly complex and multimorbid (Fraser et al. 2015; Fraser et al. 2016; Tonelli et al. 2018). Given this context, the main focus of this paper will be on how we as clinicians can help people with CKD generally, rather than on the specific context of people on KRT, which has its own unique challenges and requires specialist input. The overall aim is to understand how we can offer the most holistic care to people with the condition.

\section{What do we mean by 'living well'?}

Before we continue it is worth considering what we mean by living well. Arguably, clinical interventions in any chronic condition could be considered as having one of two broad aims:

1. To reduce the risk of adverse events occurring in the future, and

2. To enhancing quality of life now.

The first might include things like prescribing statins for secondary prevention of cardiovascular disease, or inhaled steroids to prevent acute exacerbations of asthma. The second may focus on trying to alleviate unpleasant symptoms, such as addressing pain or breathlessness, providing rehabilitation to improve function, or adjusting medications that are causing side effects. We will use this framework to consider how, within the specific context of CKD, we can advise patients on living well by reducing the risk of various adverse future events and optimising quality of life. In order to do this we must understand the implications of having CKD

\section{Living with CKD - the patients' perspective}

\section{Awareness of kidney function and CKD}

In understanding patients' experiences of living with CKD, it is worth bearing in mind the public understanding of kidneys and their function. In 2014, as part of the UK 'Think Kidneys' programme, over 2000 UK residents were surveyed on their knowledge and understanding of kidneys, with results weighted for key demographic characteristics. This survey found that only $51 \%$ of people knew that kidneys make urine (the figure was 59\% among graduates), $60 \%$ knew that the kidneys help remove waste, $12 \%$ knew that kidneys have a role in processing medicines, only $1 \%$ thought that smoking endangers kidney health and more than $60 \%$ thought alcohol endangers kidney health (Slevin and Talor 2015). ${ }^{15}$

It is also worth remembering that a significant proportion of people with mild or moderate CKD may be unaware that they have the condition. In the Renal Risk in Derby study, a cohort of about 1700 people with CKD stage 3 recruited from primary care, $41 \%$ were unaware of their CKD diagnosis at baseline (Mclntyre et al. 2012).

\section{Patients' experience of living with CKD}

A systematic review and meta-ethnography of ten qualitative studies involving a total of 596 patients with non-KRT requiring CKD identified seven themes that express the experience of being diagnosed and living with the condition (Teasdale et al. 2017). These are summarised in Table 1 and show that many patients find receiving the diagnosis difficult, worry about its causation and have important concerns about future risk. They are often concerned about the way in which CKD will limit their life and feel that they have insufficient information with which to address these concerns. A further level of 
complexity in identifying the best ways of supporting patients is the relatively high prevalence of low health literacy, particularly among some more vulnerable groups of people with CKD (Taylor et al. 2017).

Table 1. Summary findings of a meta-ethnography of the experience of being diagnosed with and living with CKD

\begin{tabular}{|c|c|}
\hline Theme & Summary aspects of the theme \\
\hline A challenging diagnosis & $\begin{aligned}- & \text { feeling well and asymptomatic when first diagnosed } \\
- & \text { feelings of shock and incomprehension about the diagnosis } \\
- & \text { uncertainty about CKD permanence }\end{aligned}$ \\
\hline $\begin{array}{l}\text { Diverse beliefs about } \\
\text { causation }\end{array}$ & $\begin{array}{l}\text { - believing CKD was a result of their own actions e.g. poor } \\
\text { eating habits and alcohol or long-term medication use. } \\
\text { - } \quad \text { attributing CKD to external factors such as heredity or as } \\
\text { the result of having other conditions such as diabetes }\end{array}$ \\
\hline $\begin{array}{l}\text { Anticipated concerns } \\
\text { about progression }\end{array}$ & $\begin{array}{ll}\text { - } & \text { concerns about future treatment } \\
\text { - } & \text { anticipated social and financial burden } \\
\text { - } & \text { being unable to continue working and/or inability to care for } \\
& \text { significant others }\end{array}$ \\
\hline $\begin{array}{l}\text { Delaying disease } \\
\text { progression }\end{array}$ & $\begin{array}{l}\text { - making adjustments to daily life to try and delay disease } \\
\text { progression e.g. lifestyle changes }\end{array}$ \\
\hline $\begin{array}{l}\text { Unmet informational } \\
\text { needs }\end{array}$ & $\begin{array}{l}\text { - common viewpoint: participants believed they had received } \\
\text { insufficient information about CKD and its progression from } \\
\text { health professionals. } \\
\text { - } \\
\text { some perceived this as a deliberate attempt to withhold } \\
\text { information }\end{array}$ \\
\hline Psychosocial impact & $\begin{array}{l}\text { - loss of freedom / restricted choices (particularly in people } \\
\text { with CKD 5) due to treatment regimens, fatigue, dietary } \\
\text { restrictions and/or dependence on others }\end{array}$ \\
\hline $\begin{array}{l}\text { Adjustment to life with } \\
\text { CKD }\end{array}$ & $\begin{array}{ll}\text { - } & \text { greater involvement with decision making } \\
\text { - } & \text { importance of community/social support } \\
\text { - } & \text { trying to live life to the full, 'carry on as normal', be positive }\end{array}$ \\
\hline
\end{tabular}

(Table data taken from: Teasdale et al 2017)

It is important to be mindful of this patient perspective when considering the more clinical implications of having CKD.

\section{What are the implications of having CKD?}

CKD and future risk

It is beyond the scope of this paper to discuss all of the measures used to assess and quantify each of the following risks, attributes and outcomes but it is helpful for all health carers to have a basic understanding (Kazmi et al. 2018).

Mortality and end stage kidney disease

As mentioned above, the two most important risk factors for mortality associated with CKD are reduced GFR and albuminuria, though the risk varies with age (see Table 2). The relative risk of mortality for people with reduced GFR remains statistically significantly higher than for their peers with better renal function, although it decreases with increasing age. However, the absolute risk associated with having reduced GFR increases considerably. There is a similar picture for albuminuria. 
Table 2. Variation in relative and absolute mortality risk by age for people with CKD

\begin{tabular}{|c|c|c|c|c|}
\hline \multirow[b]{2}{*}{ Age } & \multicolumn{2}{|c|}{$\begin{array}{l}\text { Reduced GFR: } \\
\text { eGFR } 45 \mathrm{~mL} / \mathrm{min} / 1.73 \mathrm{~m}^{2} \\
\text { vs. } 80 \mathrm{~mL} / \mathrm{min} / 1.73 \mathrm{~m}^{2}\end{array}$} & \multicolumn{2}{|c|}{$\begin{array}{c}\text { Albuminuria: } \\
\text { uACR of } 300 \mathrm{mg} / \mathrm{g} \text { vs. } 10 \mathrm{mg} / \mathrm{g}\end{array}$} \\
\hline & $\begin{array}{c}\text { Relative } \\
\text { (adjusted HR } \\
(95 \% \mathrm{Cl}))\end{array}$ & $\begin{array}{c}\text { Absolute } \\
\text { (excess deaths per } \\
1000 \text { person-years } \\
(95 \% \mathrm{Cl}))\end{array}$ & $\begin{array}{c}\text { Relative } \\
\text { (adjusted HR } \\
(95 \% \mathrm{Cl}))\end{array}$ & $\begin{array}{c}\text { Absolute } \\
\text { (excess deaths per } \\
1000 \text { person-years } \\
(95 \% \mathrm{Cl})) \\
\end{array}$ \\
\hline $18-54$ & $3.50(2.55-4.81)$ & $9.0(6.0-12.8)$ & $2.53(2.13-3.03)$ & $7.5(4.3-11.9)$ \\
\hline $55-64$ & $2.21(2.02-2.41)$ & $12.2(10.3-14.3)$ & $2.30(1.84-2.88)$ & $12.2(7.9-17.6)$ \\
\hline $65-74$ & $1.59(1.42-1.77)$ & $13.3(9.0-18.6)$ & $2.10(1.83-2.44)$ & $22.7(15.3-31.6)$ \\
\hline$\geq 75$ & $1.35(1.23-1.48)$ & $27.2(13.5-45.5)$ & $1.73(1.45-2.05)$ & $34.3(19.5-52.4)$ \\
\hline
\end{tabular}

(Table data taken from: Hallan et al. 2012)

For any outcome in CKD, there are issues of competing risks. For example, if assessing the risk of progression to ESKD, account needs to be taken of the competing risk of death (i.e. that individuals die before they 'have the opportunity' to experience the outcome of ESKD). Bansal et al. (2015) developed a score to predict risk of mortality among older patients with CKD. The model includes age, sex, race, eGFR, urine albumin-to-creatinine ratio, smoking, diabetes mellitus, and history of heart failure and stroke. Similarly, Tangri et al. (2011) developed a kidney failure risk equation for prediction of progression to ESKD. Adoption of these risk scores to evaluate the relative risks of death versus ESKD has been proposed by the European Renal Best Practice Group as part of a Clinical Practice Guideline on the management of older patients with chronic kidney disease stage $3 \mathrm{~b}$ or higher (Farrington et al 2017).

Cardiovascular disease and cardiovascular death

For the majority of people with CKD, risk of cardiovascular disease is substantially higher than risk of ESKD (Chronic Kidney Disease Prognosis Consortium 2010; van der Velde et al. 2011; Matsushita et al. 2015). Following evidence that they improve prediction accuracy, eGFR and urinary albumin to creatinine ratio (UACR) are recommended to be included in cardiovascular risk prediction models (Matsushita et al. 2015). The CKD Prognosis Consortium has developed a risk scoring tool that simultaneously estimates the risk of death, cardiovascular events and ESKD, though this is applicable only to persons with CKD category G4 (Grams et al. 2011).

Hospitalisation

A large UK study showed that among 15,336 participants aged 75 years and older from 53 UK general practices, dipstick-positive proteinuria and $/$ or eGFR $<30 \mathrm{ml} / \mathrm{min} / 1.73 \mathrm{~m}^{2}$ was associated with an increased risk of single and multiple hospitalization after adjustment for age, sex and cardiovascular risk factors (Nitsch et al. 2011). After full adjustment the hazard ratio for hospitalisations during less than six months of follow-up was $1.66(95 \% \mathrm{Cl}, 1.21-2.27)$ for eGFR $<30 \mathrm{~mL} / \mathrm{min} / 1.73 \mathrm{~m}^{2}$ compared with eGFR of $60-74 \mathrm{~mL} / \mathrm{min} / 1.73 \mathrm{~m}^{2}$. Dipstick-positive proteinuria was also associated with an increased hazard ratio for admission (HR, 1.29 [95\% Cl, 1.11-1.49]) (Nitsch et al. 2011).

Acute kidney injury 
A further CKD Prognosis Consortium study involving eight general-population cohorts $(1,285,049$ participants) and five chronic kidney disease (CKD) cohorts (79,519 participants), showed that lower eGFR and higher uACR were both strongly and independently associated with AKI (Grams et al. 2015). Compared with eGFR of $80 \mathrm{~mL} / \mathrm{min} / 1.73 \mathrm{~m}^{2}$, the adjusted hazard ratio of AKI at eGFR of

$45 \mathrm{~mL} / \mathrm{min} / 1.73 \mathrm{~m}^{2}$ was $3.35(95 \% \mathrm{Cl}, 2.75-4.07)$ and compared with a uACR of $5 \mathrm{mg} / \mathrm{g}$, the risk of AKI at uACR of $300 \mathrm{mg} / \mathrm{g}$ was $2.73(95 \% \mathrm{Cl}, 2.18-3.43)$. Older age was also associated with higher risk of AKI (Grams et al. 2015).

\section{Inequalities}

Age represents one of the key inequalities in CKD. It is beyond the remit of this paper to describe all aspects of CKD inequality, but they include greater prevalence in lower socioeconomic groups, variation in prevalence and progression by ethnicity and sex. More women have kidney disease, but more men start dialysis and people from South Asian and Black backgrounds are more likely to start dialysis than people from White backgrounds (Caskey and Dreyer 2019).

\section{Comorbidities}

As suggested above, comorbidities are common in people with CKD and are associated with polypharmacy (Fraser et al. 2015). They are an important determinant of adverse outcomes and this is true not only for the 'usual suspects' that we expect in the context of CKD - diabetes and cardiovascular conditions - but also for conditions that have been considered 'discordant', such as dementia and cancer (Tonelli et al. 2015).

Some specific comorbidities and other attributes are considered below.

\section{Quality of life}

Quality of life tends to be poorer for people with CKD than their general population peers (Perlman et al. 2005). Quality of life scores also tend to decline with decreasing GFR (Perlman et al. 2005 and Mujais et al. 2009). In a large North American cohort study of people with CKD 3-5, other associations of poor quality of life included being female and having comorbidities (particularly diabetes and cardiovascular disease, including heart failure) (Mujais et al. 2009). It is notable that physical functioning scores also declined progressively with more advanced stages of CKD in this cohort and that lower quality of life was associated with anaemia and beta blocker use (Mujais et al. 2009). Decline in functional capacity, often linked to the presence of comorbidities, is also associated with worsening renal function (Chin et al 2014).

\section{Pain}

The prevalence of chronic pain in people with CKD stages 1- 4 has been estimated at about $70 \%$ in two US studies, with musculoskeletal the most common cause (Davison et al. 2014). However, there is wide variation in prevalence estimates, potentially dependent on population studied and definition of pain. In the UK, a cohort study using repeat pain medication to define pain among people with CKD stage 3 identified a prevalence of about 30\% (Fraser et al. 2015). In the Tonelli et al. (2015) large database study from Canada ( $n=530,771$ with CKD), where 'chronic pain' was based on clinical codes, the prevalence of painful condition was nearer to $10 \%$.

\section{Depression}

Depression is also common among people with CKD. In a review of eight studies of people with CKD stage 2-5 (total $n=11,501$ ), depression prevalence varied between 21 and 47\% (Shirazian et al. 2017). Outcomes associated with depression in these studies included hospitalization, ESKD, AKI, worse QoL, faster / greater decline in GFR and mortality (Shirazian et al. 2017). The Tonelli et al (2015) study, where again depression was based on ICD codes, identified a depression prevalence of $11.3 \%$ and in the Renal Risk in Derby study, where depression was based on antidepressant medication prescription, it was even lower at about 5\% (Fraser et al. 2015). These latter studies with more restricted definitions, 
almost certainly represent an under-estimation of the true prevalence. The prevalence reported in the eight-study review is not dissimilar to estimated prevalence in the England general population, reported to be about $27 \%$ among people aged over 65 years (Feng at al. 2015).

\section{Functional limitation}

CKD seems to be associated with an adverse impact on Activities of Daily Living (ADL). For example, a Korean cohort of 984 people with varying degree of renal function impairment followed for five years found that the incidence of ADL/ instrumental activities of daily living (IADL - activities that support independent living) decline was $13 \%, 12.5 \%$ and $29.5 \%$ in participants who showed improvement, no change, and decline in GFR respectively $(p=0.01)$ (Chin et al. 2014). An Alabama cohort exploring the impact on IADL and basic activities of daily living (BADL - self care tasks) conducted over two years had similar findings, with adjusted odds ratios for CKD vs. non-CKD IADL and BADL decline of 1.83 (95\% confidence intervals $(\mathrm{Cl}) 1.06-3.17, p=0.03)$ and $2.46(1.19-5.12, p=0.02)$, respectively (Bowling et al. 2011).

\section{Frailty}

Frailty may be more common among people with CKD than people without. Among 5808 adults in a cross sectional US study, prevalence of frailty was $15 \%$ in people with CKD versus $6 \%$ in those without $(p<0.001)$. After multivariable adjustment for comorbidity, CKD remained significantly associated with frailty (odds ratio $1.76 ; 95 \% \mathrm{Cl} 1.28$ to 2.41 ) (Shlipak et al. 2004). More work is needed on the relationship between CKD and frailty to explore the direction of causality.

\section{Fatigue}

Fatigue is common - particularly among people with advanced CKD (Artom et al. 2014). Prevalence estimates vary between about $40 \%$ and $90 \%$ depending on stage of CKD, measurement instruments used and treatment modality (for those on dialysis).

\section{Treatment burden and polypharmacy}

Treatment burden can be defined as the workload of healthcare, or the 'work of being a patient', and its impact on patient functioning and wellbeing (Shippee et al. 2012 and Sav et al. 2015). Activities such as taking and managing multiple medications, organising and attending healthcare appointments, monitoring health, performing self-care, and modifying lifestyle behaviours all contribute to this workload. This includes polypharmacy, but goes beyond it to consider issues which can be very burdensome for patients, such as making dietary modifications and attending multiple appointments with different specialists. While by no means unique, such things are very common among the mostly older population of people with CKD, who are frequently managing multiple conditions (Fraser et al. 2015; Fraser et al. 2016; Tonelli et al. 2018).

\section{Living well with CKD}

\section{What can we do as clinicians?}

Awareness of the patient perspective and using clear communication

Given the potential for a low level of understanding of kidneys and kidney disease, it is vital that we understand something of the patient perspective described above. We can use this knowledge to inform both what we say and how we approach clinical interactions. It is important to ask ourselves questions such as:

- 'Is this patient aware of their CKD diagnosis?'

- 'What do they understand about their condition?'

- 'What is the patient's main concern?' 
- 'What might they need to know?

- 'How can I enhance health literacy here?' (rather than 'how can I dumb this down so that people understand?')

- 'Have I checked back that they understand?'

Having our own uncertainties about CKD as a condition risks adding further to patients' concerns. ${ }^{15}$

Advice for patients

There are important things we can advise our patients. These are summarised in Table 3, categorised according to reducing future risk and enhancing quality of life. Some aspects, such as encouraging physical activity, appear in both categories.

Table 3. Things that people with chronic kidney disease and clinicians can do to support 'living well' with the condition

\begin{tabular}{|c|c|c|}
\hline & $\begin{array}{r}\text { Patients } \\
\end{array}$ & $\begin{array}{l}\text { Clinicians } \\
\end{array}$ \\
\hline \multirow[t]{6}{*}{$\begin{array}{l}\text { Reducing } \\
\text { future risk }\end{array}$} & $\begin{array}{l}\text { Undertake monitoring, particularly } \\
\text { of their own blood pressure }\end{array}$ & $\begin{array}{l}\text { Regular monitoring, particularly albuminuria, } \\
\text { eGFR and blood pressure }\end{array}$ \\
\hline & $\begin{array}{l}\text { Lifestyle measures: dietary sodium } \\
\text { restriction, weight loss, exercise }\end{array}$ & $\begin{array}{l}\text { Cardiovascular risk assessment (including } \\
\text { use of risk prediction tools) and management: } \\
\text { smoking cessation, blood pressure control, } \\
\text { use of statins, diabetes control, proteinuria } \\
\text { control }\end{array}$ \\
\hline & $\begin{array}{l}\text { Enquiring about progression and } \\
\text { other risks - enhancing health } \\
\text { literacy }\end{array}$ & $\begin{array}{l}\text { Careful assessment of CKD progression risk } \\
\text { relative to other risks e.g. kidney failure risk } \\
\text { equation (Tangri et al. 2011). }\end{array}$ \\
\hline & $\begin{array}{l}\text { Understanding purpose of } \\
\text { medicines and avoiding nephrotoxic } \\
\text { medicines - enhancing health } \\
\text { literacy, discuss treatment burden } \\
\text { with clinicians }\end{array}$ & $\begin{array}{l}\text { Careful medicines management including } \\
\text { appropriate dose adjustments and } \\
\text { minimisation of polypharmacy }\end{array}$ \\
\hline & $\begin{array}{l}\text { Understanding need for and } \\
\text { engaging with activity - enhancing } \\
\text { health literacy }\end{array}$ & $\begin{array}{l}\text { Encouraging (and potentially referring for) } \\
\text { exercise to improve mobility and strength }\end{array}$ \\
\hline & $\begin{array}{l}\text { Fluid management, avoiding } \\
\text { nephrotoxic medicines, flu } \\
\text { vaccination, medication adherence, } \\
\text { potentially temporary avoidance of } \\
\text { certain medications when sick } \\
\text { (though caution in heart failure) }\end{array}$ & $\begin{array}{l}\text { Good clinical care to reduce acute kidney } \\
\text { injury risk e.g. fluids, sepsis management, } \\
\text { avoiding nephrotoxic medications }\end{array}$ \\
\hline \multirow[t]{2}{*}{$\begin{array}{l}\text { Enhancing } \\
\text { quality of life }\end{array}$} & $\begin{array}{l}\text { Understanding CKD - enhancing } \\
\text { health literacy through asking about } \\
\text { the diagnosis }\end{array}$ & $\begin{array}{l}\text { Careful explanation of the CKD diagnosis and } \\
\text { its likely causality }\end{array}$ \\
\hline & $\begin{array}{l}\text { Enquiring about progression and } \\
\text { other risks - enhancing health } \\
\text { literacy }\end{array}$ & $\begin{array}{l}\text { Careful explanation of progression risk } \\
\text { relative to other risks (CVE, death before } \\
\text { ESKD). Most people with CKD are at low risk } \\
\text { of progressing to ESKD. Adapt information } \\
\text { provided according to the dominant risk. }\end{array}$ \\
\hline
\end{tabular}




\begin{tabular}{|l|l|l|}
\hline & $\begin{array}{l}\text { Understanding purpose of } \\
\text { medicines, monitoring and } \\
\text { appointments and querying } \\
\text { unnecessary visits. Developing } \\
\text { strategies / routines to manage } \\
\text { treatment burden }\end{array}$ & $\begin{array}{l}\text { Assessing overall treatment burden (consider } \\
\text { using a validated measure) }\end{array}$ \\
\cline { 2 - 3 } $\begin{array}{l}\text { Enhancing patient activation } \\
\text { balanced with burden } \\
\text { Consider the importance of peer } \\
\text { support either 'formal' (e.g. via } \\
\text { kidney care networks) or informal } \\
\text { e.g. social networks. }\end{array}$ & $\begin{array}{l}\text { Supporting self-management without } \\
\text { overloading the patient }\end{array}$ \\
\cline { 2 - 2 } $\begin{array}{l}\text { Understanding purpose of } \\
\text { medicines - enhancing health } \\
\text { literacy }\end{array}$ & $\begin{array}{l}\text { Careful medicines management including } \\
\text { appropriate dose adjustments and } \\
\text { minimisation of polypharmacy }\end{array}$ \\
\hline $\begin{array}{l}\text { Understanding need for and } \\
\text { engaging with activity - enhancing } \\
\text { health literacy }\end{array}$ & $\begin{array}{l}\text { Encouraging (and potentially referring for) } \\
\text { exercise to improve mobility and strength }\end{array}$ \\
\hline $\begin{array}{l}\text { Inform clinicians about pain. } \\
\text { Consider non-pharmacological } \\
\text { solutions for pain }\end{array}$ & $\begin{array}{l}\text { Adequately address pain. } \\
\text { Consider non-pharmacological solutions for } \\
\text { pain }\end{array}$ \\
\hline
\end{tabular}

\section{Conclusions}

CKD is a condition with both specific and general health risks. The population of people with CKD tends to have more challenges across a number of domains than their peers. Helping people with the condition to live well includes considering ways of reducing future risk and enhancing quality of life. Patients can, and should, be actively engaged in this in order to enhance their capacity to manage the condition and reduce the burden both of the disease and its treatment.

\section{Five to eight key points which summarize the major themes of your article:}

1. Key issues reported by patients with CKD include being shocked by the diagnosis, being uncertain about the cause, worry about progression and concerns about future treatment and its anticipated social and financial burden.

2. Helping people to live well with a chronic condition like CKD should include efforts to reduce the risk of adverse events occurring in the future, and consider what can be done to enhance quality of life now.

3. As clinicians we can help people live well with CKD by being aware of their perspective and communicating clearly, including checking their understanding, particularly of the CKD diagnosis, its likely causality and the risk of progression. 
4. People with CKD commonly suffer from multiple comorbidities and lower quality of life, often experiencing chronic pain, depression, functional limitation, frailty, fatigue and high treatment burden.

5. Assessing overall treatment burden is an important component of management.

6. Reduced glomerular filtration rate and presence of albuminuria are both associated with increased risk of several poor outcomes including cardiovascular disease, hospitalisation, acute kidney injury and death.

7. Interventions to reduce future risk in CKD include regular monitoring (particularly albuminuria, eGFR and blood pressure), careful assessment of CKD progression risk relative to other risks, and careful medicines management.

8. Non-pharmacological interventions that may improve mobility, strength and pain should be considered.

\section{Conflicts}

The authors declare no conflicts of interest 


\section{References}

Artom M, Moss-Morris R, Caskey F, Chilcot J. 2014. Fatigue in advanced kidney disease. Kidney International; 86 (3): 497-505

Astor BC, Matsushita K, Gansevoort RT, van der Velde M, Woodward M, Levey AS, Jong PE, Coresh $\mathrm{J}$; the Chronic Kidney Disease Prognosis Consortium. 2011. Lower estimated glomerular filtration rate and higher albuminuria are associated with mortality and end-stage renal disease. A collaborative meta-analysis of kidney disease population cohorts. Kidney Int;79(12): 1331-40.

Bansal N, Katz RDe Boer IH et al. 2015. Development and validation of a model to predict 5-year risk of death without ESRD among older adults with CKD. Clin J Am Soc Nephrol; 10: 363-371

Bowling C, Sawyer P, Campbell R, Ahmed A, Allman RM. 2011. Impact of chronic kidney disease on activities of daily living in community-dwelling older adults. J Gerontol A Biol Sci Med Sci;66(6):689-94.

Caskey F, Dreyer G. 2019. Kidney health inequalities in the UK; reflecting on the past, reducing in the future. Kidney Research UK.

Chin H, Ahn S, Ryu J, Kim S, Na KY, Kim KW, Chae DW, Kim CH, Kim KI. 2014. Renal function and decline in functional capacity in older adults. Age Ageing;43:833-8.

Chronic Kidney Disease Prognosis Consortium, Matsushita K, van der Velde M, Astor BC, Woodward M, Levey AS, de Jong PE, Coresh J, Gansevoort RT. 2010. Association of estimated glomerular filtration rate and albuminuria with all-cause and cardiovascular mortality in general population cohorts: a collaborative meta-analysis. Lancet;375(9731): 2073-81.

Davison SN, Koncicki H, Brennan F. 2014. Pain in chronic kidney disease: a scoping review. Semin Dial.;27(2):188-204

Farrington K, Covic A, Nistor I et al. 2017. Clinical Practice Guideline on management of older patients with chronic kidney disease stage $3 b$ or higher (eGFR $<45 \mathrm{~mL} / \mathrm{min} / 1.73 \mathrm{~m} 2$ ): a summary document from the European Renal Best Practice Group. Nephrol Dial Transplant 1;32(1):9-16.

Feng Y, Devlin N, Herdman M. 2015. Assessing the health of the general population in England: how do the three- and five-level versions of EQ-5D compare? Health Qual Life Outcomes 13:171

Fraser SD, Roderick PJ, Aitken G, Roth M, Mindell JS, Moon G, O'Donoghue D. 2014. Chronic kidney disease, albuminuria, and socioeconomic status in the Health Surveys for England 2009 and 2010. Journal of Public Health 36(4):577-86.

Fraser SDS, Roderick PJ, May C, McIntyre N, Mclntyre C, Fluck RJ, Shardlow A, Taal MW. 2015. The burden of comorbidity in people with chronic kidney disease stage 3: a cohort study. BMC Nephrology 16:193

Fraser SDS, Taal MW. 2016. Multimorbidity in people with chronic kidney disease: implications for outcomes and treatment. Current Opinion in Nephrology \& Hypertension;25(6):465-472

Gansevoort RT, Matsushita K, van der Velde M, Astor BC, Woodward M, Levey AS, Jong PE, Coresh $\mathrm{J}$; the Chronic Kidney Disease Prognosis Consortium. 2011. Lower estimated GFR and higher 
albuminuria are associated with adverse kidney outcomes. A collaborative meta-analysis of general and high-risk population cohorts. Kidney Int;80(1): 93-104.

Grams ME, Sang Y, Ballew SH, et al. 2018. Predicting timing of clinical outcomes in patients with chronic kidney disease and severely decreased glomerular filtration rate. Kidney International 93(6):1442-1451

Grams ME, Sang Y, Ballew SH, Gansevoort RT, Kimm H, Kovesdy CP, Naimark D, Oien C, Smith DH, Coresh J, Sarnak MJ, Stengel B, Tonelli M; the Chronic Kidney Disease Prognosis Consortium. 2015. A Meta-analysis of the Association of Estimated GFR, Albuminuria, Age, Race, and Sex With Acute Kidney Injury. AJKD 66(4): 591-601.

Hallan SI, Matsushita K, Sang Y, Mahmoodi BK, Black C, Ishani A, Kleefstra N, Naimark D, Roderick P, Tonelli M, Wetzels JF, Astor BC, Gansevoort RT, Levin A, Wen CP, Coresh J; Chronic Kidney Disease Prognosis Consortium. 2012. Age and association of kidney measures with mortality and end-stage renal disease. JAMA 308(22):2349-60.

Hirst JA, Montes MDV, Taylor CJ, Ordóñez-Mena JM, Ogburn E, Sharma V, Shine B, James T, Hobbs FR. Impact of a single eGFR and eGFR-estimating equation on chronic kidney disease reclassification: a cohort study in primary care. Br J Gen Pract. 2018;68(673):e524-e530

Hounkpatin HO, Harris S, Fraser SDS, Day J, Mindell JS, Taal MW, O'Donoghue D, Roderick PJ. 2020. Prevalence of chronic kidney disease in adults in England: comparison of nationally representative cross-sectional surveys from 2003 to 2016 . BMJ Open in press

Kazmi I, Gullapudi L, Taal MW. 2018. What every doctor needs to know about chronic kidney disease. Br J Hosp Med (Lond) 79(8):438-443.

KDIGO 2012 Clinical Practice Guideline for the Evaluation and Management of Chronic Kidney Disease. 2013. Kidney International Supplements 3:136-150

Matsushita K, Coresh J, Sang Y, Chalmers J, Fox C, Guallar E, Jafar T, Jassal SK, Landman GW, Muntner P, Roderick P, Sairenchi T, Schöttker B, Shankar A, Shlipak M, Tonelli M, Townend J, van Zuilen A, Yamagishi K, Yamashita K, Gansevoort R, Sarnak M, Warnock DG, Woodward M, Ärnlöv J; the Chronic Kidney Disease Prognosis Consortium. 2015. Estimated glomerular filtration rate and albuminuria for prediction of cardiovascular outcomes: a collaborative meta-analysis of individual participant data. Lancet Diabetes Endocrinol 3(7): 514-525

Mclntyre NJ, Fluck R, Mclntyre C, Taal M. 2012. Treatment needs and diagnosis awareness in primary care patients with chronic kidney disease. Br J Gen Pract 62(597):e227-32

Moynihan R, Glassock R, Doust J. 2013. Chronic kidney disease controversy: how expanding definitions are unnecessarily labelling many people as diseased. BMJ 347:f4298.

Mujais SK, Story K, Brouillette J, Takano T, Soroka S, Franek C, Mendelssohn D, Finkelstein FO. 2009. Health-related quality of life in CKD patients: Correlates and evolution over time. Clin J Am Soc Nephrol 4: 1293-1301

Nitsch D, Nonyane BA, Smeeth L, Bulpitt CJ, Roderick PJ, Fletcher A. 2011. CKD and hospitalization in the elderly: a community-based cohort study in the United Kingdom. Am J Kidney Dis. May;57(5):66472. 
Perlman RL, Finkelstein FO, Liu L, Roys E, Kiser M, Eisele G, Burrows-Hudson S, Messana JM, Levin N, Rajagopalan S, Port FK, Wolfe RA, Saran R. 2005. Quality of life in chronic kidney disease (CKD): A cross-sectional analysis in the Renal Research Institute-CKD study. Am J Kidney Dis; 45: 658-666

Sav A, King MA, Whitty JA, Kendall E, McMillan SS, Kelly F, Hunter B, Wheeler AJ. 2015. Burden of treatment for chronic illness: a concept analysis and review of the literature. Health Expect.18(3):31224.

Shippee ND, Shah ND, May CR, Mair FS, Montori VM. Cumulative complexity: a functional, patientcentered model of patient complexity can improve research and practice. J Clin Epidemiol. 2012;65(10):1041-51.

Shirazian S, Grant CD, Aina O, Mattana J, Khorassani F, Ricardo AC. 2017. Depression in Chronic Kidney Disease and End-Stage Renal Disease: Similarities and Differences in Diagnosis, Epidemiology, and Management. Kidney Int Rep 2(1): 94-107.

Shlipak MG, Stehman-Breen C, Fried LF, Song X, Siscovick D, Fried LP, Psaty BM, Newman AB: The presence of frailty in elderly persons with chronic renal insufficiency. Am J Kidney Dis 43 : 861- 867, 2004

Slevin J, Taylor A. 2015. Understanding what the public know about their kidneys and what they do. Findings from Ipsos MORI survey 2014. Think Kidneys programme.

Tangri N, Stevens LA, Griffith J, Tighiouart H, Djurdjev O, Naimark D, Levin A, Levey AS. 2011. A predictive model for progression of chronic kidney disease to kidney failure. JAMA; 305: 1553-1559

Taylor D, Fraser SDS, Bradley JA, Bradley C, Draper H, Metcalfe W, Oniscu G, Tomson C, Ravanan R, Roderick PJ. 2017. A systematic review of the prevalence and associations of limited health literacy in chronic kidney disease. Clin J Am Soc Nephrol; 12(7):1070-1084.

Teasdale E, Leydon G, Fraser SD, Roderick PJ, Taal MW, Tonkin-Crine S. 2017. Patients' Experiences after CKD Diagnosis: A Meta-ethnographic Study and Systematic Review. Am J Kidney Dis 70(5):656665.

Tonelli M, Wiebe N, Guthrie B, James MT, Quan H, Fortin M, Klarenbach SW, Sargious P, Straus S, Lewanczuk R, Ronksley PE, Manns BJ, Hemmelgarn BR. 2015. Comorbidity as a driver of adverse outcomes in people with chronic kidney disease. Kidney Int, 88:859-866.

Tonelli M, Wiebe N, Manns BJ, Klarenbach SW, James MT, Ravani P, Pannu N, Himmelfarb J, Hemmelgarn BR. 2018. Comparison of the complexity of patients seen by different medical subspecialists in a universal health care system. JAMA Netw Open. 1(7):e184852.

van der Velde M, Matsushita K, Coresh J, Astor BC, Woodward M, Levey A, de Jong P, Gansevoort RT; the Chronic Kidney Disease Prognosis Consortium. 2011. Lower estimated glomerular filtration rate and higher albuminuria are associated with all-cause and cardiovascular mortality. A collaborative meta-analysis of high-risk population cohorts. Kidney Int 79(12): 1341-52. 